\title{
Incorporação da temática das Plantas Alimentícias Não Convencio- nais (PANC) na produção científica: um estudo em teses e dissertações
}

\author{
Incorporation of the theme of Unconventiona Food Plants (ufp) in scientific production: a
} study in theses and dissertations

\author{
Ítalo de Paula Casemiro \\ Mestre em Administração \\ Universidade Federal do Rio de Janeiro \\ itcasemiro@hotmail.com \\ Ana Lucia do Amaral Vendramini \\ Doutora em Bioquímica \\ Universidade Federal do Rio de Janeiro \\ alavendra@eq.ufrj.br
}

\section{Resumo}

As Plantas Alimentícias Não-Convencionais (PANC) ainda são um tema em ascensão no contexto científico brasileiro, até mesmo por ser uma temática recente (inserida a partir do ano de 2007 pelo pesquisador Valderly Ferreira Kinupp). Nesta pesquisa, apresentamos os resultados de um estudo cujo objetivo foi de mapear a produção científica sobre PANC em dissertações e teses produzidas em programas de pós-graduação no Brasil. Adotou-se uma abordagem qualitativa, por meio de uma pesquisa documental. A busca foi realizada no Catálogo de Teses e Dissertações da Coordenação de Aperfeiçoamento de Pessoal de Nível Superior - CAPES, onde foram encontradas 41 dissertações e 14 teses que tratavam como foco principal as PANC. Os resultados das análises feitas mostraram que: a) o desenvolvimento de teses na temática teve crescimento gradual a partir de 2011, atingindo, no ano de 2017, 17 defesas; b) destacam-se como produtoras dessas teses e dissertações as instituições localizadas na região Sudeste do Brasil, especialmente a Universidade Federal de Lavras; c) as pesquisas na área de Ciências Agrárias é a principal, quando tratamos do tema por área do conhecimento, com destaque também para as pesquisas nas áreas de Ciência de Alimentos e interdisciplinares. Além desses achados identificamos que, a maior parte das pesquisas foram desenvolvidas por muIheres, além disso, a principal pesquisadora do tema é: Luciane Vilela Resende com cinco trabalhos orientados. Dentre as pesquisas encontradas também foi possível notar que, ampla maioria foram conduzidas por mulheres (42). O autor mais citado é Valdely Ferreira Kinupp. O mapeamento realizado possibilitou identificar a produção realizada no período analisado e identificar que, a temática das PANC está sendo desenvolvida por pesquisadores em importantes instituições de pesquisa no país.

Palavras-chave

Plantas Alimentícias Não-Convencionais. Bibliometria. Pesquisa Documental. Dissertações. Teses.

\section{Abstract}

Introduction: PANC - Unconventional Food Plants are still a growing topic in the Brazilian scientific context, even because it is a recent theme (inserted in 2007 by researcher Valderly Ferreira Kinupp). In this research, we present the results of a study whose approach focuses on the investigation of the scientific production of dissertations and theses on PANC. Objective: Map the scientific production on PANC in dissertations and theses produced in graduate programs in Brazil. Methodology: A qualita- 
tive approach was adopted, through documentary research. The search was carried out in the Catalog of Theses and Dissertations of the Coordination for the Improvement of Higher Education Personnel-CAPES, where 41 dissertations and 14 theses were found that addressed PANC as the main focus. Results: the results, of the analyzes made, showed that: a) the development of theses on the subject had a gradual growth from 2011, reaching, in 2017, 17 defenses; b) institutions located in the Southeast of Brazil stand out as producers of these theses and dissertations, especially the Federal University of Lavras; c) research in the area of Agrarian Sciences is the main one, when we deal with the topic by area of knowledge, with emphasis also on research in the areas of Food Science and interdisciplinary. In addition to these findings, we identified that most of the research was carried out by women, in addition, the main researcher on the topic is: Luciane Vilela Resende with five oriented works. Among the researchers found, it was also possible to note that a large majority were conducted by women (42). The most cited author is Valdely Ferreira Kinupp. Conclusions: The mapping carried out made it possible to identify the production carried out in the analyzed period and to identify that the PANC theme is being developed by researchers at important research institutions in the country.

\section{Keywords}

Unconventional Food Plants. Bibliometrics. Documentary Research. Dissertations. Theses.

\section{INTRODUÇÃO}

As universidades e institutos de ensino e pesquisa do Brasil são os principais responsáveis pelo desenvolvimento científico nacional. Neste contexto, as dissertações e teses produzidas nestas instituições, fruto de longas pesquisas, refletem parte do esforço da pesquisa brasileira na elucidação de questões e temas de interesse da sociedade. Para Leite Filho (2008), os programas de pós-graduação são os formadores de pesquisadores, professores, mestres e doutores contribuem para produção do conhecimento. Partindo desta constatação, devemos também ressaltar que os pesquisadores e os programas determinam as temáticas de estudo, ou seja, o que interessa e o que não interessa para o meio acadêmico no que concerne ao investimento em pesquisa.

Neste cenário, as PANC - Plantas Alimentícias Não-Convencionais ainda são um tema em desenvolvimento no cenário científico nacional, até mesmo por ser uma temática recente (inserida a partir do ano de 2007 pelo pesquisador Valdely Ferreira Kinupp, ver KINUPP, 2007). Devemos salientar que, plantas não-convencionais já são amplamente pesquisadas no Brasil, contudo, o uso do conceito de PANC ainda está sendo inserido no meio acadêmico.

Nesta pesquisa, apresentamos os resultados de um estudo cuja abordagem volta-se para a análise da produção e comunicação científica de dissertações e teses sobre PANC, por meio de uma bibliometria. A questão que norteou esta pesquisa foi: como está caracterizada a produção científica brasileira a respeito das PANC nos programas de pósgraduação ofertados no Brasil?

Algumas indagações levaram ao desenvolvimento desta pesquisa, tais como: quais as características gerais da produção científica sobre PANC no Brasil? Quais as temáticas estão sendo tratadas pelas pesquisas? Como o meio acadêmico tem se apropriado do tema para produzir conhecimento? Quais instituições, dentro o universo de organizações de pesquisa no Brasil, têm se dedicado à temática das PANC? Desde que o termo foi cunhado em 2007, como ele vem sendo explorado desde então? Nosso interesse em analisar a produção dos programas de pós-graduação, reside na contribuição efetiva desses programas para o desenvolvimento de temáticas de interesse da sociedade brasileira. Além disso, se faz 
importante compreender se novos conceitos, como o de PANC, estão sendo apropriados e incorporados nas pesquisas científicas.

Assim, nosso objetivo geral é realizar um estudo bibliométrico, identificando as características das teses e dissertações produzidas no Brasil sobre Plantas Alimentícias Não Convencionais, publicadas entre os anos de 2008 e 2018. Quanto aos objetivos específicos, destacamos: a) elaborar os indicadores bibliométricos (tipo de produção, distribuição temporal e geográfica, instituição, programas de pós-graduação e orientadores, etc.) nas teses e dissertações recuperadas e; b) apresentar o cenário da produção científica nacional sobre PANC a partir das teses e dissertações do Catálogo de Teses e Dissertações da Coordenação de Aperfeiçoamento de Pessoal de Nível Superior - CAPES.

\section{REFERENCIAL TEÓRICO}

\subsection{A Temática das Plantas Alimentícias Não-Convencionais - PANC}

Já se passaram pouco mais de dez anos que o termo PANC (Plantas Alimentícias NãoConvencionais) foi cunhado pelo pesquisador Valdely Kinupp em 2007 em sua tese de doutorado (KINUPP, 2007). Exatos sete anos após a criação do termo foi lançado o livro "Plantas Alimentícias Não Convencionais (PANC) no Brasil: guia de identificação, aspectos nutricionais e receitas ilustradas" (KINUPP; LORENZI, 2014) que deu maior difusão ao tema. Segundo Kinupp e Lorenzi (2014), as PANC são aquelas espécies que estão presentes na natureza, mas que a maioria das pessoas não conhece, não usa e não chegam aos pratos porque não são produzidas e ofertadas no comércio. Para Biondo et al (2018, p. 64-65), as PANC são definidas como:

\footnotetext{
Espécies cujas partes consumidas não são comuns ou convencionalmente conhecidas. Neste conceito incluem-se todas aquelas espécies com tubérculos, caules, foIhas, botões florais, flores, pólen e frutos potencialmente comestíveis, mas que não são reconhecidas como tal em determinadas regiões. São espécies com grande importância ecológica e econômica, por serem adaptadas a condições de solo e clima local, características importantes para o melhoramento genético.
}

Atualmente estamos imersos num mercado agroalimentar que estimula a adoção de dieta monótona e sem vínculo com a cultura e o território, provocando aquilo que Balem e Silveira (2005), denominam de erosão cultural alimentar, que consiste no processo de simplificação da dieta e do abandono da produção para subsistência, com uma perda gradativa da alimentação variada e nutricionalmente complexa. O impacto deste fenômeno é mais notório no meio rural, onde encontram-se as comunidades tradicionais e os agricultores familiares de diferentes origens, os quais a história está intimamente ligada as práticas alimentares. Ranieri (2017, p. 08) reconhece que,

\footnotetext{
Para o ambiente, produzir uma PANC significa reconhecer espécies nativas cujo uso está desaparecendo e valorizar a nossa biodiversidade, porque muitas delas ainda são subutilizadas como alimento. Muitas plantas não convencionais, por sua resistência e produção variada, garantem um alimento saudável, disponível o ano todo e sem grande custo.
}

Como destacam Borges e Silva (2018), temos um atual cenário, onde as PANC apresentam uma grande possibilidade para o campo alimentar, para a promoção da segurança 
alimentar, para a reafirmação da soberania alimentar entre tantas outras possibilidades. Os estudos sobre as PANC ainda são incipientes no contexto nacional, mas é perceptível o crescimento da pesquisa sobre o tema nos últimos anos, fruto do interesse da academia sobre o tema. É fundamental a produção de mais pesquisas sobre o tema, assim como a difusão científica do assunto na sociedade brasileira (BORGES; SILVA, 2018).

\subsection{Teses e Dissertações - Artefatos de conhecimento científico}

De acordo com a Associação Brasileira de Normas Técnicas (ABNT, 2011), as dissertações e teses são documentos que representam um trabalho experimental ou de exposição de um estudo científico de tema único e bem limitado. A dissertação evidencia a capacidade do autor de reunir, analisar e interpretar as informações, já a elaboração da tese exige que o tema seja original, constituindo-se em real contribuição para a especialidade em questão (ABNT, 2011). Dentro da cadeia de produção científica decorrente das pesquisas, esse tipo de literatura (teses e dissertações) "representa a culminação de um ciclo de estudo que demanda esforços, recursos e tempo dos candidatos a pesquisadores" (IGAMI, FUNARO, BRESSIANI, 2014, p. 685), sendo também uma forma de comunicação científica (BUENO, 2010).

Por outro lado, o contexto em que são produzidas as dissertações e teses, de modo geral, situa-se nos programas de pós-graduação que, por sua vez, estão vinculados, no Brasil, à Coordenação de Aperfeiçoamento de Pessoal de Nível Superior (CAPES), órgão do Ministério da Educação que efetua um rigoroso processo de avaliação periódica desses programas. Esse processo compreende a realização do acompanhamento anual e da avaliação trienal do desempenho de todos os programas e cursos que integram o Sistema Nacional de PósGraduação no país; os resultados são expressos pela atribuição de uma nota na escala de 1 a $7^{1}$. Nos últimos anos, o aumento no número de cursos em nível de pós-graduação no Brasil foi expressivo, e esse crescimento gerou forte crescimento qualitativo e quantitativo da produção científica nacional (BRASIL, 2016).

As universidades brasileiras são as grandes responsáveis pelo desenvolvimento da pesquisa científica em todas as áreas do conhecimento no Brasil, e parte significativa do conhecimento científico é produzida nos programas de pós-graduação ofertados por estas instituições (RODER; SILVA, 2013). Cabe destacar que, no Brasil, as instituições públicas de ensino, são as grandes responsáveis pela produção científica nacional (CROSS; THOMSON; SIBCLAIR, 2018).

No universo bibliográfico, as teses e dissertações são consideradas itens de literatura não convencional ou "literatura cinzenta" entendida como "o conjunto de documentos impressos ou multicopiados que não são nem editados, nem difundidos comercialmente" (CUNHA; CAVALCANTI, 2008, p. 230) devido às suas características de publicação e comunicação, sendo uma das principais o fato de não participarem do circuito comercial, o que dificultava a consulta e o acesso (IGAMI, FUNARO, BRESSIANI, 2014, p. 686). Como afirmam BoteIho e Oliveira (2017, p. 511), a literatura cinzenta "apresenta informação e conhecimento altamente atualizados e mais detalhados, alcançam um público reduzido e não são determinadas apenas por interesses comerciais." Além disso, as teses e dissertações, tratam-se de documentos primários, isto é, englobam resultados de pesquisas (MEDEIROS, 2009).

\footnotetext{
1 Informações sobre o processo de avaliação podem ser obtidas no link: https://www.gov.br/capes/ptbr/acesso-a-informacao/perguntas-frequentes/avaliacao-da-pos-graduacao. Acesso em: 24 dez. 2020.
} 
Dadas suas características, as dissertações e teses constituem matéria-prima de qualidade para a elaboração de indicadores científicos, o que comprova o potencial desse tipo de literatura (IGAMI, FUNARO, BRESSIANI, 2014).

No cenário nacional, há um grande gargalo entre o que se pesquisa e os problemas que precisamos resolver. Sobre este fato, Soares $(2018$, p. 292) levanta o seguinte questionamento:

Se a capacidade humana de concentrar esforços e recursos tem um poder de realização científica e tecnológica tão grande e surpreendente, por que não se organiza esse esforço, destinando tais competências e recursos para a solução de alguns problemas críticos que afetam a humanidade, especialmente no que diz respeito a suprimento de água e de alimento, em programas de educação, de saúde, de saneamento e qualidade ambiental?

Certamente, não estamos aqui transferindo a culpa para os pesquisadores, na verdade, eles são apenas parte de um contexto macro que está "associado à conformação social em que esses pesquisadores estão inseridos, em algumas porcentagens as pesquisas são realizadas no intuito de atender às demandas associadas à economia, ou seja, o interesse de mercado faz existir uma urgência em produção" (PINTO; VALADÃO; DE MELO, 2018, p.10). A ciência no Brasil tem abordado temas de forma reducionista, por meio de segmentos tradicionais, disciplinares e cartesianos como a ciências duras (física, química, biologia, etc.) e, conduzidas por pesquisadores limitados às tradições departamentais vigentes nas instituições de ensino e pesquisa no Brasil (SOARES, 2018).

Uma das formas de compreender a dinâmica de produção científica sobre determinados temas e áreas, é por meio de estudos métricos. Técnicas como a cienciometria e a bibliometria, que trataremos no próximo tópico, nos auxiliam nesta tarefa.

\subsection{A Bibliometria}

Ao lado de outros tipos de métodos para a avaliação do conhecimento científico, como a cienciometria e a infometria, a bibliometria é um recurso importante para medir produção científica e fazer análise de dados bibliográficos. "A bibliometria é uma área de estudos da ciência da informação que tem por objetivo analisar a atividade científica pelo estudo quantitativo das publicações" (SOUZA et al, 2017, p. 495). Quando falamos em bibliometria, estamos tratando de "um conjunto de procedimentos de pesquisa em evolução contínua" (OLIVEIRA et al, 2018a, p. 06) e que podem ser utilizados para "avaliação quantitativa de publicações científicas e tecnológicas, permitindo o estudo de suas relações e interações". (ALENCAR et al, 2017, p. 04).

O método bibliométrico utiliza-se de importantes ferramentas para avaliar e quantificar o conhecimento, sendo um método bem sucedido em diferentes contextos de investigação como forma de analisar dados referentes ao número de publicações e identificar autores mais citados, instituições de pesquisa e tópicos de investigação (BRAMNESS et al., 2013). Entre os estudos bibliométricos há três leis consagradas na literatura: 1) Lei de Bradford produtividade de periódicos; 2) Lei de Lotka - produtividades de autores e 3) Lei de Zipf frequência de ocorrência de palavras.

Mattedi e Spiess (2017, p. 624) observam que a bibliometria "constitui o resultado da progressiva convergência da estatística, da sociologia e da informática para avaliar pesquisadores, equipes ou instituições" e que os procedimentos bibliométricos "vêm ganhando cada 
vez mais importância porque oferecem um conjunto de informações sintéticas e factuais da dinâmica de funcionamento da comunidade científica."

Pereira, Ferreira Júnior e Hayashi (2013, p. 186) enfatizam que a técnica da bibliometria permite:

Mapear e quantificar os processos de comunicação científica e entender a influência de autores e instituições na produção acadêmica. Ela possibilita traçar a evolução histórica do tema de pesquisa e as associações entre grupos de pesquisadores da área, suas filiações institucionais e as temáticas de seus estudos.

Segundo Romanowski e Ens (2006, p. 41), "esses estudos possibilitam uma visão geral do que vem sendo produzido na área e uma ordenação que permite aos interessados perceberem a evolução das pesquisas, bem como suas características e foco". Pesquisas no intuito de avaliar a produção científica, justificam-se por fazerem um balanço de determinada área do conhecimento, com a finalidade de reconhecer temáticas de relevância, identificar assuntos que estão em ascensão, organizar as informações e localizar lacunas a serem pesquisadas, com a possibilidade de promoverem a evolução das pesquisas em relação ao assunto em pauta (BROIETTI; SANTIN FILHO; PASSOS, 2011). E, devemos lembrar que, o ciclo da produção de conhecimento científico incorpora desde a produção, a publicação até a sua utilização por outros pesquisadores (RODER; SILVA, 2013, p. 114).

Análises de produções científicas são muito comuns na literatura científica, tanto nacional, quanto internacional, sendo possível encontrar estudos que analisam a produção científica sobre temas diversos (MARCELO; HAYASHI, 2013; PIZZOL et al, 2015; BASTOS; REJOWSKI, 2015; ZHONG et al, 2016; IIZUKA; MORAES; SANTOS, 2015; OLIVEIRA et al, 2018b; OKUMUS et al, 2018; MUSSA; DA HORA; CORDEIRO, 2018), de artigos em periódicos (SILVEIRA; MARTINS, 2016; KRAUSKOPF, 2017; FAVARETTO; FRANCISCO, 2017; MOTTA; IIZUKA, 2018) e de produções de docentes (SOUZA; MURCIA; BORBA, 2008; LOPES, 2014; HADDAD; MENA-CHALCO; SIDONE, 2017) por exemplo. As análises da produção científica a partir de documentos mais densos como teses e dissertações também é encontrada na literatura.

Diversos autores já desenvolveram estudos sobre a produção científica dos mais variados temas, utilizando-se de técnicas bibliométricas e, analisando produções científicas como teses e dissertações, mas na literatura nacional até o presente momento, ainda não há nenhum estudo que analisa a produção sobre a temática das PANC, que é o foco do presente estudo. É importante destacar que, o conceito de PANC, por ser difundido apenas no contexto nacional, não apresenta produção científica relevante no contexto internacional.

\section{METODOLOGIA}

A fim de atender ao objetivo proposto, realizou-se uma pesquisa descritiva e com procedimento documental de abordagem qualitativa e quantitativa. "A pesquisa documental compreende o levantamento de documentos que ainda não foram utilizados como base de uma pesquisa" (MEDEIROS, 2009, p. 35). Partimos do pressuposto que o ano de 2007 foi o marco inicial do estudo sobre PANC, visto que neste ano foi criado e difundido o termo a partir da tese do professor Valdely Ferreira Kinupp (KINUPP, 2007), além disso, os documentos coletados foram aqueles referentes ao intervalo entre 2007 e 2018.

A Coordenação de Aperfeiçoamento de Pessoal de Nível Superior - CAPES desenvolveu o Catálogo de Teses e Dissertações ${ }^{2}$, um sistema online, com o propósito de comunicar

\footnotetext{
${ }^{2}$ Disponível em: https://catalogodeteses.capes.gov.br/catalogo-teses/\#!/. Acesso em: 24 ago. 2019.
} 
os resultados das pesquisas realizadas no âmbito dos programas brasileiros de pósgraduação stricto sensu para a comunidade acadêmica e facilitar o acesso às teses e dissertações defendidas nesses programas, onde é possível obter informações sobre ano da defesa, autor da tese/dissertação, orientador e co-orientador, nome do programa e instituição em que foi defendida, área de concentração entre outras informações, além do documento na íntegra (CAPES, 2017). Cabe destacar que, alguns documentos não estão disponíveis, principalmente aqueles anteriores ao início das atividades da plataforma no ano 2002 (CAPES, 2018).

É importante ressaltar que, apesar de existirem outras bases como a Biblioteca Digital de Teses e Dissertações (BDTD) do Instituto Brasileiro de Informação em Ciência e Tecnologia, a base da CAPES, numa consulta prévia, retornou um número maior de estudos que esta base, por isso a opção pela base da CAPES.

O Catálogo de Teses e Dissertações da CAPES, ao reunir em um único lugar as teses e dissertações brasileiras, apresenta-se como um importante repositório da produção científica nacional, possibilitando a comunicação científica de uma forma mais abrangente, dando visibilidade à produção nacional, além de possibilitar o acesso a dados bibliométricos sobre as produções. Devemos ressaltar que, atualmente (2019), o Catálogo de Teses e Dissertações da CAPES conta com mais de 259 mil teses e mais de 800 mil dissertações, produzidas nos mais diversos programas de pós-graduação do Brasil.

O levantamento das teses e dissertações sobre PANC ocorreu em novembro de 2018 seguindo alguns critérios. Foram utilizados os seguintes termos de busca como estratégia para recuperar os documentos no Catálogo de Teses e Dissertações da CAPES: "Hortaliça Não-Convencional"; "Hortaliças Não-Convencionais"; "Planta Alimentícia NãoConvencional"; "Plantas Alimentícias Não-Convencionais"; "PANC" e "PANCs". Estes temos foram definidos, por meio de uma consulta prévia à literatura, onde notou-se estes temos como os mais comumente aplicados para o tema em questão.

Para a identificação e seleção das teses e dissertações com a temática desejada, levou-se em consideração primeiramente o título, o resumo e as palavras-chave, sendo feita em alguns casos leitura de partes dos documentos. Assim, foram selecionadas teses e dissertações que de fato trataram sobre PANC, descartando aquelas em que o foco não é a temática, pois apenas mencionaram esporadicamente o tema. Depois desta etapa, os dados dos documentos que possibilitaram a geração de indicadores bibliométricos foram sistematizados em planilha do software Microsoft Excel e documentos do Microsoft Word, a análise temática dos trabalhos coletados foi feita com o auxílio do software Wordle com posterior análise e interpretação com base nos indicadores apresentados no Quadro 1.

Quadro 1 - Indicadores Bibliométricos Utilizados na Pesquisa

\begin{tabular}{|l|l|}
\hline \multicolumn{1}{|c|}{ Indicador } & \multicolumn{1}{c|}{ Descrição } \\
\hline Tipo de documento & Dissertação e tese \\
\hline Distribuição temporal e geográfica & Localizar trabalhos de acordo com ano e local \\
\hline Orientador & Identificar os pesquisadores mais produtivos \\
\hline Gênero & $\begin{array}{l}\text { Identificar o gênero do autor e do orientador (feminino ou mas- } \\
\text { culino) }\end{array}$ \\
\hline Formação & $\begin{array}{l}\text { Análise do perfil de formação dos autores das teses e disserta- } \\
\text { ções }\end{array}$ \\
\hline Instituições & $\begin{array}{l}\text { Identificar as instituições de ensino, nas quais as dissertações e } \\
\text { teses foram desenvolvidas }\end{array}$ \\
\hline Programa de Pós-Graduação & Nome do Programa de Pós-Graduação \\
\hline Área do Programa & Área definida pela CAPES \\
\hline
\end{tabular}




\begin{tabular}{|l|l|}
\hline Área Básica & Área básica, onde o programa está inserido \\
\hline Nota do Programa & Nota atribuída pela CAPES \\
\hline Ano de Defesa & Ano de conclusão da pesquisa \\
\hline Local da Instituição & Cidade e Estado \\
\hline PANC & Identificar as PANC estudadas nos trabalhos coletados \\
\hline Palavras-chave & Identificar as temáticas abordadas nas pesquisas \\
\hline
\end{tabular}

Fonte: Elaborado pelos autores (2019).

\section{RESULTADOS}

Como já discutido na metodologia, para a recuperação dos trabalhos (teses e dissertações) utilizadas na pesquisa, fizemos uma busca por meio de termos no Catálogo de Teses e Dissertações da CAPES. Os termos e número de trabalhos encontrados estão sintetizados no Tabela 1, a seguir.

Tabela 1 - Teses e Dissertações Recuperadas e Selecionadas para Análise

\begin{tabular}{|c|c|c|c|c|}
\hline Termos de Busca & $\begin{array}{c}\text { Teses Recupera- } \\
\text { das }\end{array}$ & $\begin{array}{c}\text { Teses Seleciona- } \\
\text { das }\end{array}$ & $\begin{array}{l}\text { Dissertações } \\
\text { Recuperadas }\end{array}$ & $\begin{array}{l}\text { Dissertações } \\
\text { Selecionadas }\end{array}$ \\
\hline $\begin{array}{l}\text { "Hortaliça Não- } \\
\text { Convencional" }\end{array}$ & 09 & & 11 & \\
\hline $\begin{array}{l}\text { "Hortaliças Não- } \\
\text { Convencionais" }\end{array}$ & 09 & & 23 & \\
\hline $\begin{array}{l}\text { "Planta Alimentí- } \\
\text { cia Não- }\end{array}$ & 01 & & 03 & \\
\hline Convencional" & & 14 & & 41 \\
\hline $\begin{array}{l}\text { "Plantas Alimen- } \\
\text { tícias Não- } \\
\text { Convencionais" }\end{array}$ & 07 & & 11 & \\
\hline "PANC" & 13 & & 19 & \\
\hline "PANCs" & 00 & & 05 & \\
\hline Totais & 39 & & 72 & \\
\hline
\end{tabular}

Fonte: Dados da Pesquisa (2018).

Ao todo, depois de excluídos os trabalhos repetidos e aqueles que não tratavam da temática em foco restaram 55 trabalhos sendo 14 teses e 41 dissertações. Também devemos destacar que, alguns trabalhos identificados não foram possíveis de serem analisados, visto que o documento na íntegra não foi disponibilizado no Catálogo de Teses e Dissertações do CAPES e nem em outros dispositivos on-line buscados pelo autor ${ }^{3}$. Durante a fase de coleta de dados entramos em contato com os autores dos trabalhos não encontrados durante as buscas, mas não obtivemos retorno da maioria deles.

No Gráfico 1 podemos notar a evolução da produção de teses e dissertações sobre PANC nos últimos anos entre os trabalhos selecionados na pesquisa. É possível verificar que, o número de trabalhos foi crescente nos últimos anos, o que demonstra a apropriação do tema pelo campo científico.

\footnotetext{
${ }^{3}$ Para acessar a lista completa de teses e dissertações utilizadas nesta pesquisa, assim como aquelas que não estavam disponíveis para análise, acesse: https://doi.org/10.7910/DVN/3WCZP8. Acesso em: 04 de abril 2019.
} 
Gráfico 1 - Dissertações e Teses sobre PANC por ano de Defesa

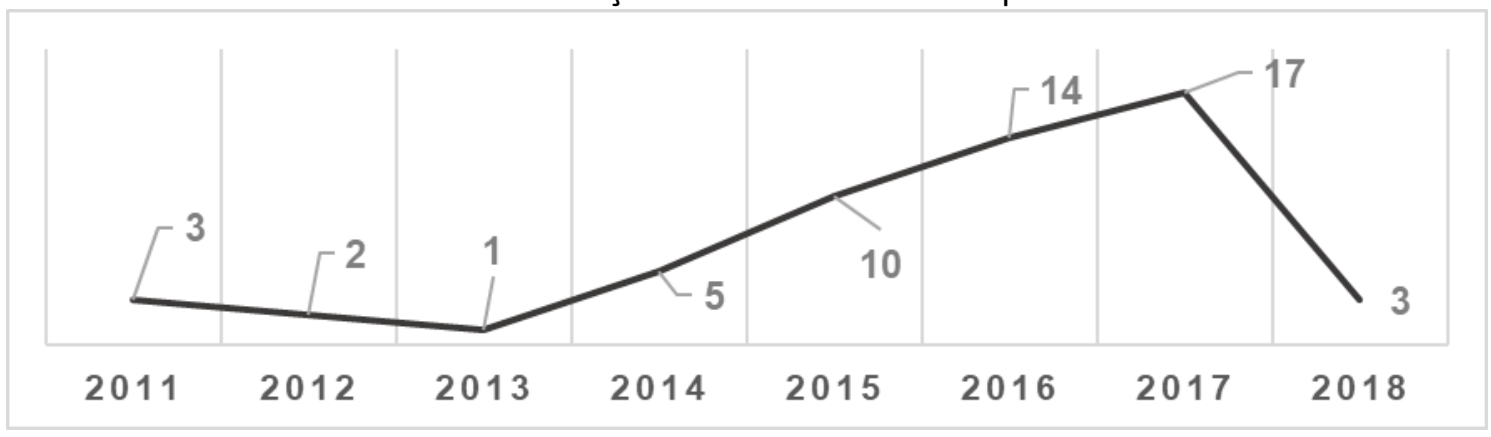

Fonte: Dados da Pesquisa (2018).

Como podemos notar, apesar do conceito de PANC ter sido divulgado em 2007, houve um aumento significativo de trabalhos sobre o tema apenas nos últimos cinco anos (2014-2017), período que representou a maior parte da produção identificada $(n=46)$ sobre o tema, sendo que, nos primeiros anos da análise (2008-2012), a produção foi correspondente a nove produções. Não foi possível identificar o motivo do crescimento de pesquisas nos últimos anos, mas temos a hipótese do aumento estar relacionado com a maior repercussão midiática do tema, criação de grupos e linhas de pesquisa sobre o tema, entre outros motivos. Devemos salientar que, como a coleta dos trabalhos ocorreu no mês de novembro de 2018, possivelmente, alguns trabalhos que foram concluídos neste ano não estão dentro da amostra coletada, visto que, entre a defesa de um trabalho e sua inserção no Catálogo de Teses e Dissertações da CAPES existe um tempo, que pode levar meses. Assim, apesar de o Gráfico 1 apresentar uma queda acentuada de produções no ano de 2018, este número pode não ser uma representação real do cenário.

Foi possível identificar que, as áreas do conhecimento que apresentam maior número de teses e dissertações produzidas sobre PANC foram as áreas de Ciências Agrária I (31 produções) e Ciência de Alimentos (oito produções).

Não podemos deixar de registrar que, de acordo com o relatório Research in Brazil: $A$ report for CAPES by Clarivate Analytics, a pesquisa sobre plantas, veterinária e agronomia são os temas onde o Brasil mais se destaca à nível mundial, juntamente com a pesquisa em medicina clínica (CROSS; THOMSON; SIBCLAIR, 2018). Também identificamos que, os trabaIhos estão predominantemente em programas da área de agronomia (27 produções).

Cabe também destacar a produção na área interdisciplinar, que também foi expressiva (quatro produções). A área interdisciplinar é especialmente desafiadora, por implicar a produção de conhecimento entre áreas diferentes e, no caso das PANC.

Como já era esperado, a maior parte dos trabalhos foram desenvolvidos na região Sudeste ( 28 trabalhos). Mas, de modo geral, há uma proliferação de pesquisas sobre o tema em todas as regiões brasileiras, apesar da distribuição desigual dos programas de pósgraduação no Brasil. É notório e, vários estudos mostram isso (SOUZA et al, 2013; CERQUEIRA, 2015; GARCIA; REDIGOLO; BENCHIMOL, 2018), que a região Sudeste concentra a grande parte da produção científica nacional, por questões diversas como maior número de programas de pós-graduação, principalmente. Infelizmente, as regiões Norte e Nordeste, apesar do potencial da biodiversidade de seus biomas, tiveram apenas quatro trabalhos identificados em cada uma. Na Figura 1 é apresentado o quantitativo de produções por Estado. 
Figura 1 - Distribuição da Produção Científica por Estado

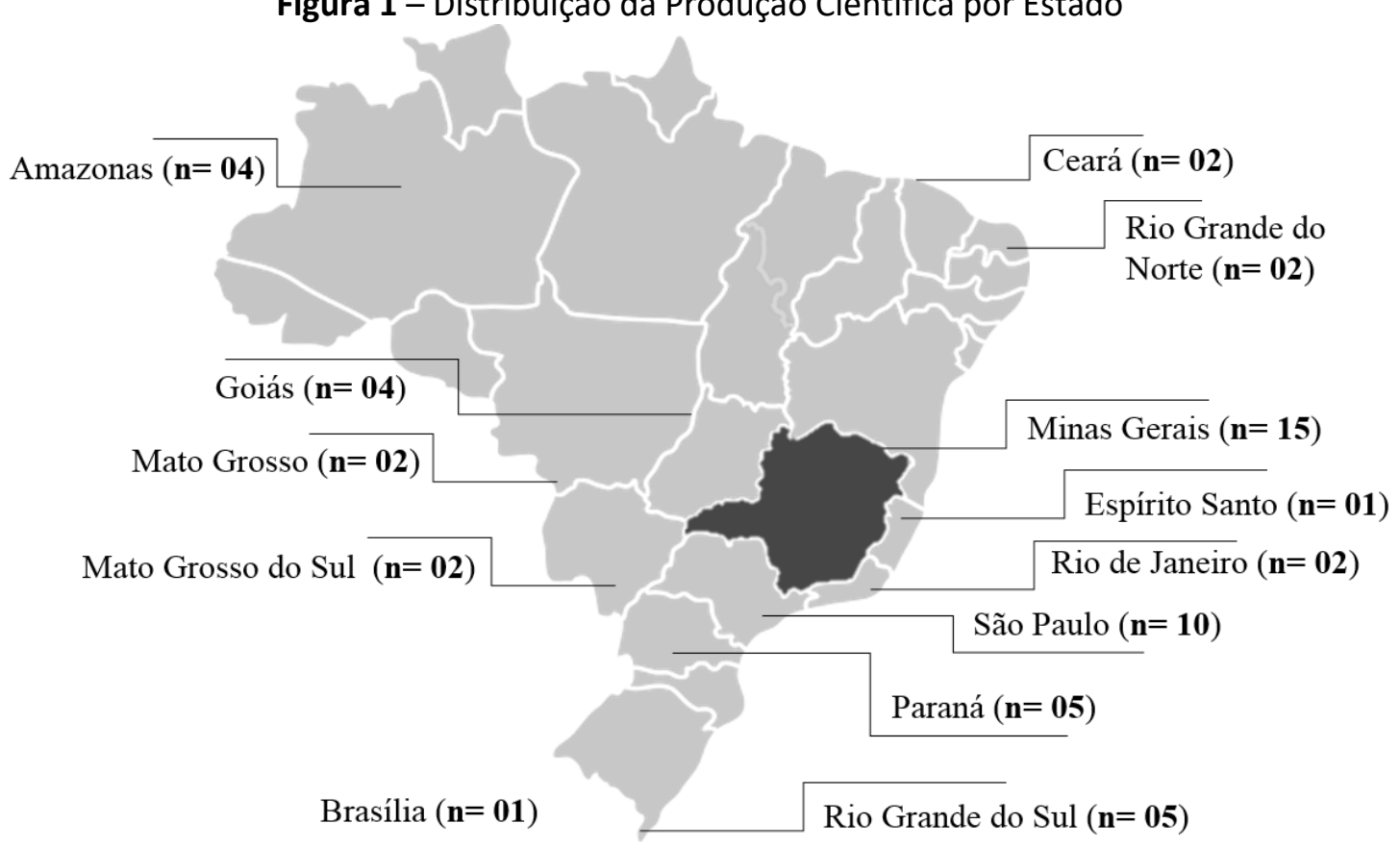

Fonte: Dados da Pesquisa (2018).

De acordo com o documento que avalia a área de Ciências Agrárias I (MEC, 2017b), a maioria dos cursos de pós-graduação estão na região Sudeste, o que justifica a maior presença de grupos nesta região. Enquanto que os cursos na área de Ciências de Alimentos estão em sua maioria distribuídos entre as regiões Sul e Sudeste (MEC, 2017c).

Como destacam Sidone, Haddad e Mena-Chalco (2016) é possível notar diferenças acentuadas entre as distribuições regionais da produção e as configurações espaciais das redes de cada área do conhecimento no contexto científico nacional, com alta heterogeneidade espacial das atividades de pesquisa e uma grande concentração na região sudeste, principalmente nas capitais dos Estados.

$\mathrm{Na}$ Tabela 2, apresentamos o ranking da produção das cinco instituições de ensino e pesquisa, que apresentaram o maior número de trabalhos sobre a temática PANC. A Universidade Federal de Lavras - UFLA destaca-se como a instituição com maior produção, sendo que de modo geral, as produções encontram-se difundidas em outras instituições. Este resultado, deve estar relacionado ao perfil da instituição, que é uma das principais instituições de pesquisa agrária do Brasil, este fato é especialmente relevante, pois demonstra que, a temática das PANC está sendo apropriada por instituições que são referência na pesquisa nas áreas de ciências agrárias I, que contempla as subáreas de Solos e Microbiologia, Extensão Rural, Melhoramento, Genética e Estatística, Engenharias Agrícola e Florestal, Proteção de Plantas e Fitotecnia (MEC, 2017b). Ainda sobre as instituições, dentre os trabalhos analisados, apenas dois deles foram desenvolvidos por instituições privadas de ensino (Universidade Vila Velha - ES e Universidade Anhanguera-Uniderp - MS).

Tabela 2 - Instituição de Ensino e Produção

\begin{tabular}{clc}
\hline Ordem & \multicolumn{1}{c}{ Instituição de Ensino } & $\mathbf{n}$ \\
\hline $\mathbf{1 0}$ & UFLA - Universidade Federal de Lavras & 9 \\
\hline $\mathbf{2 0}$ & UNESP - Universidade do Estado de São Paulo & 7 \\
\hline $\mathbf{3 0}$ & IFGO - Instituto Federal de Educação, Ciência e Tecnologia de Goiás & 3 \\
\hline $\mathbf{4 0}$ & UFPR - Universidade Federal do Paraná & 3 \\
\hline
\end{tabular}


Fonte: Dados da Pesquisa (2018).

Na Tabela 3 apresentamos os quatro programas de pós-graduação com maior produção sobre PANC e as notas dos programas, onde as pesquisas encontradas foram desenvolvidas. Ao todo, foram identificados 39 programas de pós-graduação nesta pesquisa com produções sobre PANC. Como podemos notar, no geral, são programas com boas avaliações pela CAPES.

Tabela 3 - Distribuição das Teses e Dissertações por Orientadores

\begin{tabular}{cccc}
\hline Programa de Pós-Graduação & Instituição & $\mathbf{n}$ & Nota - CAPES \\
\hline Agronomia/Fitotecnia & UFLA & 4 & 5 \\
\hline Ciência dos Alimentos & UFLA & 3 & 6 \\
\hline Agronomia (Horticultura) & UNESP & 3 & 5 \\
\hline Olericultura & IFGO & 3 & 3 \\
\hline
\end{tabular}

Fonte: Dados da Pesquisa (2018).

Entre os docentes que conduzem pesquisas sobre o tema, verificamos que não há uma grande concentração ou docente que se destaque pela produção científica sobre PANC, contudo, notamos que, o programa de pós-graduação em Agronomia/Fitotecnia da Universidade Federal de Lavras - UFLA possui a maior produção científica sobre o tema no país (quatro produções), e a docente Luciane Vilela Resende deste programa é a pesquisadora responsável pelo maior número de produções encontradas na pesquisa (com duas teses e três dissertações orientadas), mas cabe ressaltar que, essa produção está direcionada para a área da Ciências Agrárias I e que a referida pesquisadora está vinculada a dois programas de pós-graduação da UFLA (Programa de Pós-Graduação Plantas Medicinais, Aromáticas e Condimentares e ao Programa de Pós-Graduação em Agronomia/Fitotecnia). Além disso, é importante destacar que a referida pesquisadora é agrônoma, mestra em agronomia e doutora em agronomia (fitotecnia) pela mesma instituição, sendo ainda Bolsista de Produtividade em Pesquisa do CNPq - Nível 2.

Com relação ao gênero dos pesquisadores e mestres e doutores formados (os autores das produções), observamos que, há uma total igualdade na questão de gênero entre os orientadores, visto que dentre os 44 orientadores identificados, 22 são homens e 22 são mulheres. Já quanto ao perfil dos autores das produções, há uma grande diferença no gênero, sendo a maioria composta por mulheres (42, sendo oito doutoras e 34 mestras).

A participação feminina na ciência, principalmente em determinadas áreas como Ciência, Tecnologia, Engenharias e Matemática - CTEM ainda é um desafio, contudo, encontramos um cenário oposto nesta pesquisa. Silva e Ribeiro (2014) analisaram a trajetória acadêmica e profissional de mulheres na ciência e, através de entrevistas com mulheres cientistas atuantes em universidades públicas e numa instituição de pesquisa do Rio Grande do Sul. Os autores afirmam que as entrevistadas destacaram um conjunto de barreiras para seguir a carreira científica, que se referiram: "à dupla jornada de trabalho, à maternidade, à produtividade em pesquisa, à competição, ao preconceito e discriminação de gênero" (SILVA; RIBEIRO, 2014, p. 464), que notoriamente são grandes desafios para a maior participação feminina na ciência.

Ao realizarmos a pesquisa, uma das indagações que nortearam a pesquisa foi: quais são os autores citados nas discussões pelos pesquisadores, para tratar de um tema ainda pouco estudado no Brasil? Como destacam Maroldi et al (2018), as citações oferecem importantes características e padrões do tipo de literatura utilizada pelos autores na produção 
científica. Na Tabela 4, apresentamos os autores mais citados, com base nas referências dos trabalhos analisados, por ordem alfabética, lembrando que, para esta avaliação foi considerado apenas o primeiro autor da produção bibliográfica e considerada as diferentes produções citadas. Como podemos perceber pelos resultados, o principal autor é Kinupp, V. F., referente ao pesquisador Valderly Ferreira Kinupp, como era esperado, visto que o autor é considerado o idealizador do termo PANC. A obra mais citada deste autor, é o livro publicado em parceria com o pesquisador Harri Lorenzi, intitulado "Plantas Alimentícias Não Convencionais (PANC) no Brasil: guia de identificação, aspectos nutricionais e receitas ilustradas"

Tabela 4 - Autores Mais Citados nas dissertações e teses

\begin{tabular}{clc}
\hline Ordem & \multicolumn{1}{c}{ Autores/obra mais citada } & Citações \\
\hline $\mathbf{1}$ & $\begin{array}{l}\text { KINUPP, V. F. Obra mais citada: Plantas Alimentícias Não Convencionais } \\
\text { (PANC) no Brasil: guia de identificação, aspectos nutricionais e receitas ilus- } \\
\text { tradas }\end{array}$ & 102 \\
\hline $\mathbf{2}$ & $\begin{array}{l}\text { ALMEIDA, M. E. F. Obra mais citada: Utilização de cactáceas do gênero Pe- } \\
\text { reskia na alimentação humana em um município de Minas Gerais }\end{array}$ & 35 \\
\hline $\mathbf{3}$ & $\begin{array}{l}\text { FAO - FOOD AND AGRICULTURE ORGANIZATION OF THE UNITED NATIONS - } \\
\text { The State of Food and Agriculture }\end{array}$ & 32 \\
\hline $\mathbf{4}$ & $\begin{array}{l}\text { ROCHA, D. R. C. Obra mais citada: Macarrão adicionado de ora-pro-nóbis } \\
\text { (Pereskia aculeata Miller) desidratado }\end{array}$ & 25 \\
\hline $\mathbf{5}$ & $\begin{array}{l}\text { TAKEITI, C.Y. Obra mais citada: Nutritive evaluation of non-conventional leafy } \\
\text { vegetable (Pereskia aculeata Miller). }\end{array}$ & 24 \\
\hline $\mathbf{6}$ & $\begin{array}{l}\text { LORENZI, H. Obra mais citada: Plantas medicinais no Brasil: nativas e exóticas } \\
\text { cultivadas }\end{array}$ & 24 \\
\hline
\end{tabular}

Fonte: Dados da Pesquisa (2018).

Entre as obras de referência (Tabela 5), como era de se imaginar, o livro "Plantas Alimentícias Não Convencionais (PANC) no Brasil: guia de identificação, aspectos nutricionais e receitas ilustradas" (KINUPP; LORENZI, 2014) é a obra mais utilizada pelos pesquisadores (30 citações). Dentre as obras mais citadas, temos apenas duas, dentre as nove primeiras, que são obras oriundas da literatura estrangeira.

Tabela 5 - Obras Mais Referenciadas

\begin{tabular}{|c|c|c|c|c|}
\hline Ordem & Título & Autores & Citações & Ano \\
\hline $1 \underline{a}$ & $\begin{array}{l}\text { Plantas alimentícias não convencio- } \\
\text { nais } \\
\text { (PANC) no Brasil: guia de identifica- } \\
\text { ção, aspectos nutricionais e receitas } \\
\text { ilustradas }\end{array}$ & KINUPP, V. F.; LORENZI, H. & 30 & 2014 \\
\hline $2^{\mathbf{a}}$ & $\begin{array}{l}\text { Nutritive evaluation of non- } \\
\text { conventional leafy vegetable } \\
\text { (Pereskia aculeata Miller). }\end{array}$ & $\begin{array}{l}\text { TAKEITI, C. Y.; ANTONIO, G. } \\
\text { C.; MOTTA, E. M. P.; COLLA- } \\
\text { RES-QUEIROZ, F. P.; PARK, K. } \\
\text { J. }\end{array}$ & 24 & 2009 \\
\hline 3a & $\begin{array}{l}\text { Manual de Hortaliças Não- } \\
\text { Convencionais }\end{array}$ & BRASIL & 19 & 2010 \\
\hline $4 \underline{a}$ & $\begin{array}{l}\text { Complexes of arabinogalactan of } \\
\text { Pereskia aculeata and } \mathrm{Co} 2+, \mathrm{Cu} 2+\text {, } \\
\mathrm{Mn} 2+\text {, and } \mathrm{Ni} 2+\text {. }\end{array}$ & $\begin{array}{lr}\text { MERCÊ, } & \text { A. } \\
\text { J.S. R.; } & \text { LANDALZE, } \\
\text { J.S. MANGRICH, } & \text { A.S.;; } \\
\text { SZPOGANICZ, } & \text { B.; } \\
\text { SIERAKOWSKI, M.R } & \end{array}$ & 18 & 2001 \\
\hline 5 & $\begin{array}{l}\text { Estudo anatômico de folha e caule de } \\
\text { Pereskia aculeata Mill. (Cactaceae) }\end{array}$ & $\begin{array}{l}\text { DUARTE, M. R.; HAYASHI, S. } \\
\text { S. }\end{array}$ & 16 & 2005 \\
\hline
\end{tabular}

Fonte: Dados da Pesquisa (2018). 
A Figura 2 feita com o auxílio do software Wordle evidencia as palavras-chave mais frequentes nos 55 trabalhos avaliados, sendo assim considerados termos aplicados pelos pesquisadores para definir as temáticas de suas pesquisas. Importante ressaltar que, as palavras em detalhe na Figura 2 são aqueles que mais surgiram entre as palavras-chave. As palavras que mais se destacaram foram hortaliças, plantas, nutricional, compostos, nãoconvencionais, pereskia, aculeata e ora-pro-nóbis, que de uma forma geral, refletem o conteúdo dos trabalhos analisados. Essas palavras-chave contemplam de forma conjunta ou individual, o escopo dos conteúdos dos trabalhos analisados. É importante observar que, para fins de padronização, alguns termos foram agrupados, por exemplo, plantas alimentícias não convencionais e seu singular foram considerados apenas como "pancs".

Figura 2 - Frequência de Palavras-Chave

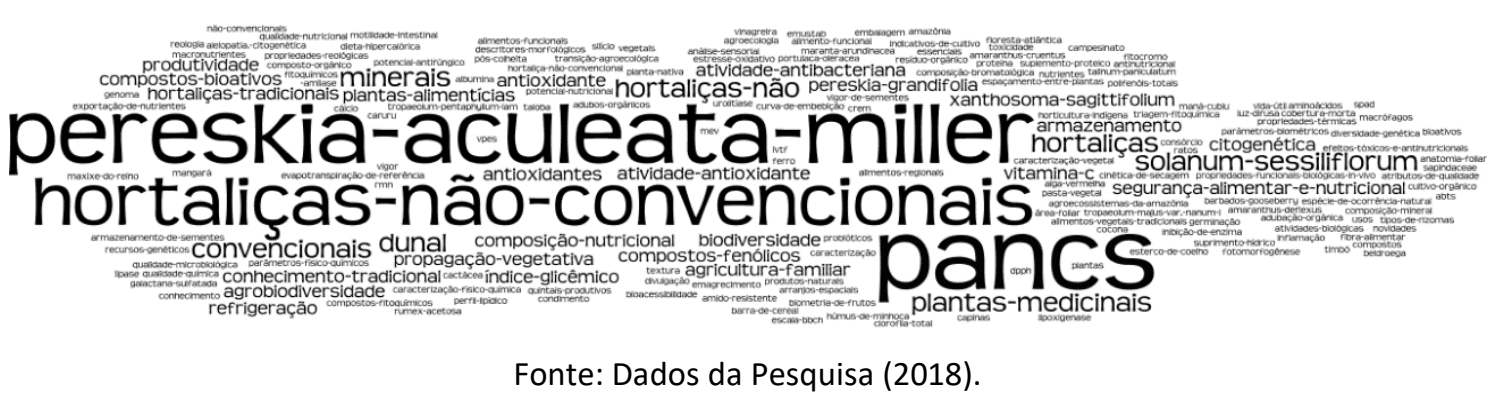

Fizemos também um breve apanhado das PANC pesquisadas. Curiosamente, existe uma concentração na produção sobre a PANC ora-pro-nóbis (Pereskia aculeata), fato este que deve estar associada ao seu rico potencial nutritivo e a outros aspectos, como fácil cultivo, difusão pelas mais diversas regiões do país, etc. Oito teses e oito dissertações tratam da ora-pro-nóbis como temática principal, no mais, o restante da produção apresenta uma boa difusão de pesquisas sobre PANC diversas como a Capuchinha (Tropaeolum majus), Taioba (Xanthosoma sagittifolium), Vinagreira (Hibiscus sabdariffa), Beldroega (Portulaca oleracea), Azedinha (Rumex acetosa $\mathrm{L}$ ) entre outras. Também devemos destacar que há três trabalhos sobre o cubiu (Solanum sessiliflorum) (três dissertações) e mais outros três sobre a araruta (Maranta arundinacea) (três dissertações).

\section{CONSIDERAÇÕES FINAIS}

O presente estudo oferece importantes contribuições para uma maior caracterização da produção científica acerca das PANC no Brasil.

No intuito de apresentar um panorama das pesquisas sobre PANC, a fim de conhecer o atual cenário dos estudos a respeito do tema, pretendemos com isso, promover o debate sobre os estudos a respeito do tema, especialmente pelo marco de 10 anos desde que o termo foi cunhado, bem como contribuir para que novos pesquisadores se interessem em pesquisar o tema em questão e possam ter uma dimensão do que o contexto acadêmico fez até o momento sobre a temática.

Os resultados evidenciam um número razoável de pesquisas sobre o tema nos últimos cinco anos. Não podemos aqui afirma se são poucas ou muitas pesquisas. Certamente não são muitas, mas para afirmar que são poucas, teríamos que fazer um estudo comparativo. A partir dos resultados podemos notar que, as PANC são um tema latente e um campo ainda em aberto e com potencial para ser explorado. 
As pesquisas que encontramos estão concentradas em duas áreas, Ciências Agrárias I e Ciência de Alimentos, com um número razoável de pesquisas na área Interdisciplinar.

Dos trabalhos existentes, como era de se esperar, a maior parte são produções do tipo dissertação, por questões óbvias, como o fato de o número de programas e de alunos de mestrado serem maiores que os de doutorado no Brasil.

Podemos observar que há uma concentração dos estudos em instituições da Região Sudeste, o que não é de se surpreender, visto que, nesta região estão concentradas grande parte das instituições de pesquisa do Brasil, assim como recursos financeiros para a pesquisa científica. Cabe aqui destacar a UFLA, como a instituição com o maior número de produções sobre o tema.

As interações entre a universidade e o conhecimento acadêmico e a sociedade nem sempre são fáceis e, muitas vezes os conhecimentos ficam restritos ao meio acadêmico ou, suas potencialidades para resolver questões sociais são pouco conhecidas ou desconhecidas pela população em geral, por conta da falta de mediação entre a universidade e a sociedade (BAUMGARTEN, 2010).

Como sugestão para futuras pesquisas, indicamos o estudo da apropriação dos conhecimentos geradas pelas dissertações e teses analisadas neste trabalho no meio social, isto é, a análise da repercussão dos estudos aqui identificados. Outra fonte de informações que podem ser exploradas, são os artigos científicos sobre o tema. Além disso, investigar as produções e linhas de pesquisas de grupos de pesquisas ou em programas de pósgraduação, poderia ser uma forma de expandir as discussões apresentadas no presente estudo.

A pesquisa sobre PANC está sendo encaminhada no cenário científico nacional, contudo, ainda vemos a necessidade da diversificação e distribuição de pesquisas por todo o Brasil, como forma de contemplar toda a nossa biodiversidade e cultura alimentar.

\section{REFERÊNCIAS}

ALENCAR, M. S. M. et al. Análise da produção científica brasileira sobre nanotecnologia e saúde. Revista Eletrônica de Comunicação, Informação \& Inovação em Saúde, v. 11, n. 1, p. 01-16, 2017. Disponível em:

https://www.reciis.icict.fiocruz.br/index.php/reciis/article/view/1199. Acesso em 12 out. 2019.

ASSOCIAÇÃO BRASILEIRA DE NORMAS TÉCNICAS (ABNT). NBR 14724 - Informação e documentação - Trabalhos acadêmicos - Apresentação. 2011.

BALEM, T.; SILVEIRA, P. R. A erosão cultural alimentar: processo de insegurança na agricultura familiar. In: CONGRESSO DA ASSOCIAÇÃO LATINO-AMERICANA DE SOCIOLOGIA RURAL, 2005. Porto Alegre. p. 4. Anais... Porto Alegre: Associação Latino-Americana de Sociologia Rural, 2005. Disponível em:

https://www.researchgate.net/publication/237676880_A_EROSAO_CULTURAL_ALIMENTAR _PROCESSO_DE_INSEGURANCA_ALIMENTAR_NA_AGRICULTURA_FAMILIAR. Acesso em 12 out. 2019.

BAUMGARTEN, M. Ciência, tecnologia e desenvolvimento-redes e inovação social. Parcerias Estratégicas, v. 13, n. 26, p. 101-124, 2010. Disponível em: 
http://seer.cgee.org.br/index.php/parcerias_estrategicas/article/viewFile/321/315. Acesso em: 12 dez. 2019.

BASTOS, S.; REJOWSKI, M. Pesquisa científica em hospitalidade: desafios em busca de uma configuração teórica. Revista Hospitalidade, v. 12, n. Especial, p. 132-159, 2015. Disponível em: https://www.revhosp.org/hospitalidade/article/view/575. Acesso em 12 out. 2019.

BIONDO, E. et al. Diversidade e potencial de utilização de plantas alimentícias não convencionais no Vale do Taquari, RS. Revista Eletrônica Científica da UERGS, v. 4, n. 1, p. 61-90, 2018. Disponível em: http://revista.uergs.edu.br/index.php/revuergs/article/view/1005. Acesso em: 13 ago. 2019.

BOTELHO, R. G.; OLIVEIRA, C. da C. de. Literaturas branca e cinzenta: uma revisão conceitual. Ciência da Informação, v. 44, n. 3, p.501-513, 2015. Disponível em: http://revista.ibict.br/ciinf/article/view/1804. Acesso em: 23 dez. 2019.

BORGES, C. K. G. D.; SILVA, C. C. Plantas alimentícias não convencionais (PANC): a divulgação científica das espécies na cidade de Manaus, AM. Revista Eletrônica Científica Ensino Interdisciplinar. Mossoró, v. 4, n. 11, p. 466-477, 2018. Disponível em: http://periodicos.uern.br/index.php/RECEI/article/view/2635. Acesso em: 16 ago. 2019.

BRAMNESS, J. G. et al. A bibliometric analysis of European versus USA research in the field of addiction. Research on alcohol, narcotics, prescription drug abuse, tobacco and steroids 2001-2011. European addiction research, v. 20, n. 1, p. 16-22, 2014. Disponível em: https://www.ncbi.nlm.nih.gov/pubmed/23921359. Acesso em 12 out. 2019.

BRASIL. Mestres e doutores 2015 - Estudos da demografia da base técnico científica brasileira. - Brasília, DF: Centro de Gestão e Estudos Estratégicos, 2016. 348 p. Disponível em: https://www.cgee.org.br/documents/10182/734063/Mestres_Doutores_2015_Vs3.pdf. Acesso em: 23 dez. 2019.

Ministério da Agricultura, Pecuária e Abastecimento. Manual de hortaliças nãoconvencionais. Brasília: Mapa/ACS, 2010. 92 p. Disponível em: <http://www.abcsem.com.br/docs/manual_hortalicas_web.pdf>. Acesso em 12 out. 2019.

BROIETTI, F. C. D.; SANTIN FILHO, O.; PASSOS, M. M. Mapeamento da produção científica brasileira a respeito do Enem (1998-2011). Revista Diálogo Educacional, v. 14, n. 41, p. 233 260, 2014. Disponível em: https://www.redalyc.org/articulo.oa?id=189130424012. Acesso em 12 out. 2019.

BUENO, W. C. Comunicação cientifica e divulgação científica: aproximações e rupturas conceituais. Informação \& Informação, v. 15, n. 1esp, p. 1-12, 2010. Disponível em: <http://www.uel.br/revistas/uel/index.php/informacao/article/view/6585>. Acesso em: 03 dez. 2020.

CAPES. Catálogo de Teses e Dissertações. Histórico e evolução. 2017. Disponível em: http://sdi.capes.gov.br/banco-de-teses/02_bt_sobre.html Acesso em: 30 nov. 2019. 
CAPES. Catálogo de Teses e Dissertações. Sobre, 2018. Disponível em: http://sdi.capes.gov.br/catalogo-teses/ct sobre.html. Acesso em 12 out. 2018.

CROSS, D.; THOMSON, S.; SIBCLAIR, A. Research in Brazil: A report for CAPES by Clarivate Analytics. Clarivate Analytics, 2018. 73 p. Disponível em: https://www.capes.gov.br/images/stories/download/diversos/17012018-CAPESInCitesReport-Final.pdf. Acesso em: 03 out. 2019.

CUNHA, M. B. da; CAVALCANTI, C. R. O. Dicionário de Biblioteconomia e Arquivologia. Brasília: Briquet de Lemos, 2008.

DAL PIZZOL, Leandro et al. Análise bibliométrica da produção científica sobre Linked Data. Informação \& Informação, v. 20, n. 3, p. 77-112, 2015. Disponível em: http://www.uel.br/revistas/uel/index.php/informacao/article/view/14426. Acesso em: 20 dez. 2019.

FAVARETTO, J. E. R.; FRANCISCO, E. de R. Exploração do acervo da RAE-Revista de Administração de Empresas (1961 a 2016) à luz da bibliometria, text mining, rede social e geoanálise. RAE-Revista de Administração de Empresas, v. 57, n. 4, p. 365-390, 2017. Disponível em: https://rae.fgv.br/rae/vol57-num4-2017/exploracao-acervo-rae-revista-administracaoempresas-1961-2016-luz-bibliometria-. Acesso em 12 out. 2019.

SILVA, F. F. da; RIBEIRO, P. R. C. Trajetórias de mulheres na ciência: "ser cientista" e "ser muIher". Ciência \& Educação (Bauru), v. 20, n. 2, p. 449-466, 2014. Disponível em: http://www.scielo.br/pdf/ciedu/v20n2/1516-7313-ciedu-20-02-0449.pdf. Acesso em: 16 ago. 2019.

HADDAD, E. A.; MENA-CHALCO, J. P.; SIDONE, O. Produção científica e redes de colaboração dos docentes vinculados aos programas de pós-graduação em Economia no Brasil. Estudos Econômicos (São Paulo), v. 47, n. 4, p. 617-679, 2017. Disponível em: http://www.scielo.br/scielo.php?script=sci_arttext\&pid=S0101-41612017000400617. Acesso em 12 out. 2019.

HEISLER, E. V. et al. Uso de plantas medicinales en el cuidado de la salud: la producción científica de tesis y disertaciones de enfermería brasileña. Enfermería Global, v. 14, n. 39, p. 390403, 2015. Disponível em: http://scielo.isciii.es/pdf/eg/v14n39/pt_revision5.pdf. Acesso em 12 out. 2019.

IGAMI, M. P. Z.; FUNARO, V. M. B. O.; BRESSIANI, J. C. Estudo longitudinal das dissertações e teses para obtenção de indicadores científicos. RBPG, Brasília, v. 11, n. 25, p. 683 - 704, 2014. Disponível em: http://ojs.rbpg.capes.gov.br/index.php/rbpg/article/view/444/pdf. Acesso em: 29 nov. 2019.

IIZUKA, E. S.; MORAES, G. H. S. M. de; SANTOS, A. A. Produção acadêmica em empreendedorismo no Brasil: análise dos artigos aprovados nos eventos da ANPAD entre $2001 \mathrm{e}$ 
2012. Administração: Ensino e Pesquisa, v. 16, n. 4, p. 723-749, 2015. Disponível em: https://raep.emnuvens.com.br/raep/article/view/383. Acesso em 12 out. 2019.

KINUPP, V. F. Plantas alimentícias não-convencionais da região metropolitana de Porto Alegre, RS Tese (Doutorado), Porto Alegre: Programa de Pós-Graduação em Fitotecnia. Universidade Federal do Rio Grande do Sul; 2007. Disponível em:

https://lume.ufrgs.br/handle/10183/12870. Acesso em: 16 ago. 2019.

KINUPP, V. F.; LORENZI, H. Plantas alimentícias não convencionais (PANC) no Brasil: guia de identificação, aspectos nutricionais e receitas ilustradas. São Paulo: Plantarum, 2014.

KRAUSKOPF, E. A bibiliometric analysis of the Journal of Infection and Public Health: 20082016. Journal of infection and public health, v. 11, n. 2, p. 224-229, 2018. Disponível em: https://www.ncbi.nlm.nih.gov/pubmed/29361505. Acesso em 12 out. 2019.

LEITE FILHO, G. A. Padrões de produtividade de autores em periódicos e congressos na área de contabilidade no Brasil: um estudo bibliométrico. Revista de Administração Contemporânea, Curitiba, v. 12, n. 2, p. 533-554, 2008. Disponível em:

http://www.scielo.br/pdf/rac/v12n2/a11v12n2.pdf. Acesso em 12 out. 2019.

LOPES, J. R. A Produção Científica dos Programas de Pós-Graduação em Ciência da Informação na Região Sudeste do Brasil. Revista lluminart, v. 1, n. 11, p. 57-71. 2014. Disponível em: http://revistailuminart.ti.srt.ifsp.edu.br/index.php/iluminart/article/view/168. Acesso em 12 out. 2019.

MARCELO, Júlia Fernandes; HAYASHI, Maria Cristina Piumbato Innocentini. Estudo bibliométrico sobre a produção científica da área da sociologia da ciência. Informação \& Informação, v. 18, n. 3, p. 138-153, 2013. Disponível em:

http://www.uel.br/revistas/uel/index.php/informacao/article/view/8413. Acesso em: 20 dez. 2019.

MAROLDI, Alexandre Masson; LIMA, Luis Fernando Maia; HAYASHI, Maria Cristina Piumbato Innocentini. Análise de Citações Presentes em Teses e Dissertações em Educação Indígena. Informação \& Informação, v. 23, n. 3, p. 177-201, 2018. Disponível em: http://www.uel.br/revistas/uel/index.php/informacao/article/view/30186/pdf. Acesso em: 20 dez. 2019.

MATTEDI, M. A.; SPIESS, M. R. A avaliação da produtividade científica. História, Ciências, Saúde - Manguinhos, Rio de Janeiro, v.24, n.3, 2017, p.623-643. Disponível em: http://www.scielo.br/pdf/hcsm/v24n3/0104-5970-hcsm-24-03-0623.pdf. Acesso em: 20 nov. 2019.

MEDEIROS, J. B. Redação Científica: a prática de fichamento, resumos, resenhas. 11 ed. - 2 . Reimpr. São Paulo: Atlas, 2009.

MINISTÉRIO DA EDUCAÇÃO - MEC. RELATÓRIO DE AVALIAÇÃO QUADRIENAL 2017 - Ciências Agrárias I. 2017b. 43 p. Disponível em: 
http://capes.gov.br/images/stories/download/avaliacao/relatorios-finais-quadrienal2017/20122017-CIENCIAS-AGRARIAS-I-quadrienal.pdf. Acesso em: 23 dez. 2019.

MINISTÉRIO DA EDUCAÇÃO - MEC. RELATÓRIO DE AVALIAÇÃO QUADRIENAL 2017 - Ciências de Alimentos. 2017c. 44 p. Disponível em: https://capes.gov.br/images/stories/download/avaliacao/relatorios-finais-quadrienal2017/20122017-CIENCIA-DE-ALIMENTOS-quadrienal.pdf. Acesso em: 23 dez. 2019.

MOTTA, A. M.; IIZUKA, E. S. Análise da Produção do Journal of Marketing de 2014 A 2016. Revista Brasileira de Marketing, v. 17, n. 4, p. 575-589, 2018. Disponível em: http://www.revistabrasileiramarketing.org/ojs2.2.4/index.php/remark/article/viewArticle/3894. Acesso em 12 out. 2019.

MUSSA, Munir de Sá; DA HORA, Henrique Rego Monteiro; CORDEIRO, Renata Gomes. Certificações de Tecnologia da Informação e Modelo de Kano: Um estudo bibliométrico. Informação \& Informação, v. 23, n. 3, p. 143-159, 2018. Disponível em: http://www.uel.br/revistas/uel/index.php/informacao/article/view/28305/pdf. Acesso em: 20 dez. 2019.

OKUMUS, B.; KOSEOGLU, M. A.; MA, F. Food and gastronomy research in tourism and hospitality: A bibliometric analysis. International Journal of Hospitality Management, v. 73, p. 6474, 2018. Disponível em:

https://www.sciencedirect.com/science/article/pii/S027843191730854X. Acesso em 12 out. 2019.

OLIVEIRA, L.D.M. et al. Pesquisa em marketing do SEMEAD. Marketing \& Tourism Review, v. 3, n. 3, p. 01-20, 2018a. Disponível em:

https://revistas.face.ufmg.br/index.php/mtr/article/view/4684. Acesso em: 23 dez. 2019.

OLIVEIRA, B. S. et al. The culinary intangible cultural heritage of UNESCO: a review of journal articles in EBSCO platform. Journal of Culinary Science \& Technology, p. 1-19, 2018b. Disponível em: https://www.tandfonline.com/doi/full/10.1080/15428052.2018.1513882. Acesso em 12 out. 2019.

PEREIRA, M. A.; FERREIRA JÚNIOR, A.; HAYASHI, M. C. P. I. Colégios jesuíticos no Brasil Colonial: análise bibliométrica de teses e dissertações. In: HAYASHI, M. C. P. I; MUGNAINI, R.; HAYASHI, C. R. M. (Org.). Bibliometria e cientometria: metodologias e aplicações. São Carlos: Pedro \& João Editores, 2013.

PINTO, B. L. S. ; VALADÃO, R. M. ; DE MELO, M. A. A publicação científica como um meio de divulgação e não como finalidade do processo de investigação. Multi-Science Journal, v. 1, n. 10, p. 1-3, 2018. Disponível em: https://www.ifgoiano.edu.br/periodicos/index.php/multiscience/article/view/528/398. Acesso em: 20 nov. 2019.

RANIERI, G. R. GUIA PRÁTICO SOBRE PANCS: plantas Alimentícias Não convencionais. 1a ed. São Paulo: Instituto Kairós, 2017. Disponível em: https://institutokairos.net/portfolio- 
items/guia-pratico-de-panc-plantas-alimenticias-nao-convencionais/. Acesso em: 23 dez. 2019.

RODER, E. dos S.F.; SILVA, E. L. da. Agricultura familiar e as teses de doutorado no Brasil. TransInformação, Campinas, v. 25, n. 2, p. 111-126, 2013. Disponível em: http://www.scielo.br/pdf/tinf/v25n2/a02v25n2.pdf. Acesso em 12 out. 2019.

ROMANOWSKI, J.; ENS, R. As pesquisas denominadas do tipo "Estado da Arte" em Educação. Diálogo Educacional, v.6, n. 19, p. 37-50, 2006. Disponível em: https://www.redalyc.org/articulo.oa?id=189116275004. Acesso em 12 out. 2019.

SILVEIRA, B. R.; SILVEIRA-MARTINS, E. Orientação empreendedora: uma análise bibliométrica em periódicos nacionais e internacionais. Revista de Administração FACES Journal, v. 15, n. 4, p. 100-126, 2016. Disponível em: http://www.fumec.br/revistas/facesp/article/view/3588. Acesso em 12 out. 2019.

SIDONE, O. J. G.; HADDAD, E. A.; MENA-CHALCO, J. P. A ciência nas regiões brasileiras: evolução da produção e das redes de colaboração científica. Transinformação, v. 28, n. 1, p. 1532, 2016. Disponível em: http://www.scielo.br/scielo.php?pid=S010337862016000100015\&script=sci_abstract\&tlng=pt. Acesso em: 20 nov. 2019.

SOARES, P. C. Contradições na pesquisa e pós-graduação no Brasil. Estudos Avançados, v. 32, n. 92, p. 289-313, 2018. Disponível em: http://www.scielo.br/pdf/ea/v32n92/0103-4014ea-32-92-0289.pdf. Acesso em: 20 nov. 2019.

SOUZA, F. C. de; MURCIA, F. Dal-Ri; BORBA, J. A. Perfil e Produtividade Científica dos Docentes de Finanças Vinculados a Doutorados em Administração. Revista de Administração FACES Journal, v. 10, n. 2, p. 17-36, 2008. Disponível em: http://www.fumec.br/revistas/facesp/article/view/622. Acesso em 12 out. 2019.

SOUZA, R. M. F. de et al. Análise Bibliométrica dos Artigos Científicos em Finanças Publicados na Revista de Administração de Empresas (RAE) da FGV/SP, no período de 2006 a 2016. Administração: Ensino e Pesquisa, v. 18, n. 3, p. 489-517, 2017. Disponível em: https://raep.emnuvens.com.br/raep/article/view/631. Acesso em: 23 dez. 2019.

ZHONG, S. et al. A bibliometric review on natural resource accounting during 19952014. Journal of cleaner production, v. 139, p. 122-132, 2016. Disponível em: https://www.sciencedirect.com/science/article/pii/S0959652616311647. Acesso em 12 out. 2019. 